\title{
PERSEPSI REMAJA TERHADAP AUTHORITATIVE PARENTING PRACTICE YANG DITERAPKAN ORANGTUA DAN INTENSI BERPERILAKU DELINKUEN
}

\author{
Dinie Ratri Desiningrum \\ Fakultas Psikologi, Universitas Diponegoro \\ Jln. Prof. Soedarto, Tembalang, Semarang, 50239, Telp/Fax (024) 7460051 \\ dn.psiundip@gmail.com
}

\begin{abstract}
ABSTRAK
Remaja merupakan fase usia transisi anak-anak menuju dewasa, dimana mereka mulai ingin menonjolkan identitas dirinya. Remaja dalam perkembangannya tetap membutuhkan arahan dan pengawasan dari orangtua, karena remaja akan banyak dipengaruhi oleh pergaulan sosial teman sebaya dalam pembentukan identitas dirinya, yang bisa mengarah pada kenakalan remaja. Penelitian ini bertujuan untuk melihat hubungan antara persepsi remaja terhadap authoritative parenting style dan intensi berperilaku delinkuen. Penelitian ini menggunakan metode korelasi kuantitatif. Populasi dalam penelitian ini adalah remaja siswa kelas IX SMPIT di tiga sekolah di Semarang dan tinggal bersama orangtua dengan jumlah populasi total 400 siswa, dan diperoleh sampel 188 siswa dengan teknik cluster random sampling. Penelitian ini menggunakan dua skala psikologis, yaitu skala persepsi remaja terhadap authoritative parenting practice orangtua dengan 39 item valid, serta skala intensi berperilaku delinkuen pada remaja dengan 35 item valid. Data penelitian diolah menggunakan analisis regresi, dengan hasil nilai signifikansi sebesar $0,000(p<0,05)$ dan korelasi $(r)=-0,228$. Artinya terdapat hubungan negatif dan signifikan antara persepsi remaja terhadap authoritative parenting practice orangtua dengan intensi dalam berperilaku delinkuen pada remaja. Temuan lain hasil penelitian ini memberikan data bahwa remaja menilai bahwa kemampuan orangtua dalam menjaga keharmonisan keluarga adalah penting, dan menurut mereka peran kedua orangtua meskipun berbeda bisa saling melengkapi.
\end{abstract}

Kata kunci: persepsi terhadap authoritative parenting practice, intensi berperilaku delinkuen, remaja

\section{THE ADOLESCENT PERCEPTION OF AUTHORITATIVE PARENTING PRACTICE IMPLEMENTED PARENTS AND THE INTENCE OF DELINQUENCY BEHAVIOR}

\begin{abstract}
Adolescence is the age phase of the transition of children to adulthood, where individuals begin to highlight their identity. Adolescence in its development process still requires direction and supervision from parents, because adolescence will be much influenced by social community of peers in the develop of identity itself, which can lead to juvenile delinquency. This study aims to examine the relationship between adolescent perceptions of authoritative parenting practice and intention to behave delinquency. This research used quantitative correlation method. The population in this study were junior high school students of three schools in Semarang and living with parents with total population are 400 students, and obtained sample of 188 students with cluster random sampling technique. This study uses two psychological scales, there are adolescent perception scale of the parenting authoritative parenting practice with 39 valid items, and the scale of intention to behave delinquent in adolescents with 35 valid items. The datas were analyzed used regression analysis, the result are significance value $0.000(p<0,05)$ and correlation $(r)=-0,228$. This means there is a negative and significant correlation between the perception of adolescents to authoritative parenting practice parents with an intention in behaving delinquent in adolescents. The other findings that subjects judge that parents' ability to maintain family harmony was important, and according to the subject of the roles of both parents though different could complement each other.
\end{abstract}

Keywords: Perception of Authoritarive Parenting, Intention of Delinquent Behavior, Adolescence 


\section{Journal of Psychological Science and Profesion (JPSP)}

Vol.2, No.1, April 2018

E-mail: jurnal.psp@unpad.ac.id

\section{PENDAHULUAN}

Masa remaja merupakan masa yang banyak menarik perhatian karena sifat-sifat khasnya dan peranannya yang menentukan kehidupan individu dalam masyarakat orang dewasa (Yusuf, 2012). Remaja merupakan masa transisi dari periode anak menuju dewasa (Sarlito, 2007). Masa remaja merupakan salah satu tahapan perkembangan manusia yang dianggap sangat penting. Remaja kerapkali mengalami kesulitan dalam kemampuan sosio-psikologis, dimana remaja cenderung sukar bersosialisasi dan mudah konflik dengan teman sebaya dan orangtua (Sviridova, Lazurenko, \& Slipka, 2016).

Masa remaja merupakan masa transisi dari masa kanak-kanak menuju masa dewasa yang berkisar antara 13 sampai 21 tahun. Pada masa ini terjadi perubahan pada individu baik secara fisik, psikis, maupun secara sosial (Steinberg, 2002). Secara psikososial, menurut Erikson (dalam Papalia, Old \& Feldman, 2009) remaja berada pada identity versus identity confusion. Masa ini merupakan periode yang sulit untuk ditempuh, baik secara individual ataupun kelompok, sehingga remaja sering dikatakan sebagai kelompok umur bermasalah (the trouble teens). Individu pada tahap ini sudah ingin menonjolkan identitas dirinya, namun masih terperangkap dalam peran yang masih kabur di lingkungannya. Bagi remaja yang tidak mampu mengatasi krisis tersebut mungkin akan memilih perkembangan yang negatif dengan cara mengambil bagian dalam tindak kenakalan sebagai usaha untuk mencapai suatu identitas peran. Pengembangan konsep diri dan identitas diri tetap menjadi hal yang perlu ada pada remaja, agar menumbuhkan kesadaran remaja dalam menghadapi berbagai tantangan dari diri dan lingkungan (Sandu, Pânişoarã, Ovidiu \& Pânişoarã 2015).

Sebagian besar waktu yang dimiliki remaja berusia 15-17 tahun, digunakan untuk kegiatan positif seperti tidur, makan, sekolah, dan kegiatan santai yang dipilih. Maka jika remaja tidak diawasi akan menggunakan waktunya untuk hal lain seperti ikut dalam pergaulan sosial teman sebaya yang bisa mengarah kepada perilaku kenakalan remaja (Wight, Price, Bianchi, \& Hunt, 2009). Pada remaja terdapat intensi untuk melakukan tindak kejahatan. Perilaku ini dinamakan perilaku delinkuen atau kenakalan remaja.

Tindak kriminalitas yang melibatkan pelajar semakin meningkat jumlahnya. Berdasarkan Survey Lentera tahun 2015, sebanyak 45 persen jumlah remaja di Indonesia pada usia 13 hingga 19 tahun sudah merokok, tahun 2016 fenomena (surabaya.tribunnews, 2016). Pelajar tidak lagi sekedar terlibat dalam aktivitas nakal seperti membolos sekolah, merokok, minum minuman keras, atau menggoda lawan jenis, tetapi tidak jarang remaja terlibat dalam penggunaan napza, pencurian kendaraan bermotor dan terjerumus dalam kehidupan seksual pranikah (Sarlito, 1999). Pengendalian diri yang rendah dikaitkan dengan berbagai perilaku antisosial pada diri remaja, sehingga remaja yang terlibat intensi berperilaku delinkuen dianggap sebagai remaja yang rendah kontrol dirinya (Meldrum, Trucco, Cope, Zucker, \& Heitzeg. 2017).

Kenakalan remaja adalah perilaku remaja yang menyalahi aturan sosial di lingkungan masyarakat tertentu. Menurut Sudarsono (2004) kecenderungan seorang individu yang masih berada dalam fase-fase usia remaja kemudian melakukan pelanggaran terhadap norma hukum, norma susila, norma agama, dan mengganggu ketentraman serta keamanan masyarakat baik yang dilakukan sendiri maupun secara berkelompok disebut dengan intensi berperilaku delinkuen. Intensi adalah posisi seseorang dalam dimensi probabilitas subjektif yang melibatkan suatu hubungan antara dirinya dengan beberapa tindakan. Intensi merupakan faktor motivasional yang mempengaruhi tingkah laku. Intensi dapat menunjukkan seberapa besar kemauan seseorang untuk berusaha melakukan suatu tingkah laku tertentu. Intensi tersebut masih merupakan disposisi untuk bertingkah laku sampai pada saat ada kesempatan yang tepat. Menelaah intensi berarti dapat memprediksi bagaimana perilaku delinkuen yang akan dilakukan oleh remaja.

Bentuk-bentuk perilaku delinkuen menurut Jensen (dalam Sarlito, 1999) adalah perkelahian, perkosaan, perampokan, pembunuhan, perusakan, pencurian, pencopetan, pemerasan, pelacuran, penyalahgunaan obat, hubungan sex pra nikah, membolos sekolah, minggat dari rumah atau membantah perintah orangtua. Fenomena ini selain tersebar secara luas di dunia juga terlihat nyata di Indonesia. Fenomena kenakalan hingga kriminalitas yang dilakukan oleh anak-anak di Indonesia semakin meningkat dari waktu ke waktu. Media massa baik media cetak maupun media elektronik hampir setiap hari memberitakan tentang terjadinya intensi berperilaku delinkuen di berbagai tempat dan di seluruh lapisan masyarakat. Maraknya intensi berperilaku delinkuen akhir-akhir ini yang dilakukan kelompok remaja merupakan sebuah kajian yang perlu untuk dibahas. Republika (2012) memberitakan bahwa salah seorang siswa SMA tidak mengikuti ujian nasional, karena harus memberikan laporan dan kesaksian di kantor polisi atas penganiayaan salah seorang guru yang menyebabkan sebelah 


\section{Journal of Psychological Science and Profesion (JPSP)}

Vol.2, No.1, April 2018

E-mail: jurnal.psp@unpad.ac.id

matanya mengalami luka, pada saat siswa lainnya mengikuti ujian.

Suatu perbuatan disebut delinkuen apabila perbuatan-perbuatan tersebut bertentangan dengan norma-norma yang ada dalam masyarakat di mana remaja tinggal, atau suatu perbuatan yang anti-sosial di mana di dalamnya terkandung unsur-unsur normatif (Sudarsono, 2004). Pada remaja, aspek sosial dan keluarga sangat berpengaruh, selain itu terdapat faktor kompetensi psikososial, kepribadian, konsep diri, dan kecerdasan yang juga ikut berpengaruh (Morgado \& Dias, 2013). Dalam penelitian lain ditemukan bahwa faktor keluarga memberi pengaruh lebih besar bagi remaja yang lebih muda (12-15 tahun), sedangkan teman sebaya menunjukkan pengaruh yang lebih besar pada remaja yang lebih tua (16-19 tahun) (José, Fraguela, Maneiro, \& Sobral, 2017).

Melalui pola asuh yang baik, remaja akan memiliki bekal dalam menghadapi berbagai pengaruh lingkungan, baik dari masyarakat maupun lingkungan yang lebih luas. Kurangnya pendidikan moral di lingkungan keluarga, perhatian dan kasih sayang orangtua, penanaman nilai-nilai moral dan agama yang minim, menjadi faktor penyebab terjadinya berbagai bentuk kondisi negatif pergaulan remaja. Hilangnya norma-norma atau nilai-nilai dominan dalam diri remaja dapat mengakibatkan remaja tidak mengenal perbuatan baik dan buruk. Remaja membutuhkan pemantauan dari orangtua untuk tumbuh dan berkembang lebih dewasa, agar terhindar dari intensi berperilaku delinkuensi, terutama pada remaja awal (AhYoo, 2017).

Nilai-nilai yang dimiliki remaja yang didapat dari didikan orangtua, digunakan remaja untuk mengatasi berbagai pengaruh negatif dari luar rumah. Dalam membentuk nilai-nilai tersebut dibutuhkan komunikasi yang baik antar anggota keluarga terutama antara orangtua-remaja secara verbal dan non verbal. Komunikasi yang terjalin antara orangtua-remaja menjadi hal yang penting terutama berperan dalam pembentukan pribadi remaja. Seperti dalam suatu hasil penelitian yang mengidentifikasi bahwa ketidakhadiran ayah bisa menjadi kontributor maraknya kenakalan remaja, artinya peran ayah dan ibu tetap dibutuhkan untuk tumbuh-kembang anak remajanya (Simmons, Steinberg, Frick, \& Cauffman, 2018).

Pengasuhan yang kasar dari orangtua (baik secara emosional maupun fisik) memiliki efek signifikan pada faktor psikososial anak (agresi dan depresi), dan agresi memberi efek signifikan pada perilaku nakal atau delinkuen (You, \& Lim, 2015). Menurut Hurlock (2009) orangtua harus dapat memberikan perlakuan yang tepat sesuai dengan perkembangan anak, agar anak dapat mempersepsikan pengasuhan yang diberikan kepadanya dengan baik sehingga dapat menunjang perkembangan psikologisnya. Perlakuan yang diberikan orangtua kepada anak salah satunya dengan parenting practices. Parenting practices merupakan praktik pengasuhan yang dilakukan oleh orangtua terhadap anak dengan adanya sikap kehangatan serta keterlibatan orangtua dalam perkembangan anak, termasuk dalam hal belajar anak (Kim \& $\mathrm{Ge}, 2008)$. Praktik pengasuhan penting untuk diteliti, karena menurut sebuah penelitian ditemukan bahwa perilaku prososial remaja banyak dibentuk oleh orangtua yang hangat dalam praktek pengasuhannya (Davisa, \& Carlo, 2018)

Remaja membutuhkan dukungan sosial, diantaranya remaja memerlukan aturan dari sekolah dan orangtua, untuk mendampinginya tumbuh, berkembang dan bersosialisasi dengan lingkungan termasuk teman sebaya, dalam hal ini diperlukan kerjasama yang baik antara pihak sekolah dan orangtua dalam mengatur remaja (Sabatine, Lippold, \& Kainz, 2017). Parenting practices merupakan perilaku atau perlakuan pengasuhan yang dilakukan orangtua dalam membesarkan anak, salah satunya pada pengasuhan authoritative. Darling dan Steinberg (1993) menyebutkan bahwa authoritative parenting merupakan pengasuhan orangtua yang mencakup dukungan emosional, standar yang tinggi, pemberian otonomi yang sesuai, dan komunikasi dua arah yang dapat membantu anakanak dan remaja dalam mengembangkan kompetensi yang ditandai dengan keseimbangan kebutuhan dan tanggung jawab baik secara sosial maupun individual.

Penelitian menunjukkan bahwa authoritative parenting practices memiliki dampak yang positif terhadap berbagai perkembangan kognitif dan sosio emosional anak dan remaja (Mayseless, Scharf, \& Sholt, 2003). Remaja memiliki energi yang besar karena berada dalam tahap pertumbuhan dan perkembangan optimal dalam kehidupannya. Maka dibutuhkan aktivitasaktivitas fisik yang memadai untuk mendukung optimalisasi perkembangan selanjutnya. Suatu penelitian menemukan bahwa tipe pola asuh yang diterapkan orangtua dapat mempengaruhi intensitas remaja dalam menggunakan waktunya untuk beraktivitas fisik (Jago, Davison, Brockman, Page, Thompson, \& Fox, 2011)

Authoritative parenting practices mampu meningkatkan self esteem remaja (Khatoon, Hesari, \& Hejazi, 2011). Riset lain menunjukkan bahwa authoritative parenting practices instruktur berpengaruh positif terhadap penyesuaian diri remaja di dunia perkuliahan, sehingga 


\section{Journal of Psychological Science and Profesion (JPSP)}

Vol.2, No.1, April 2018

E-mail: jurnal.psp@unpad.ac.id

menumbuhkan pemberdayaan pada diri remaja (Cakır, 2015).

Steinberg \& Silk (2002) mendefinisikan authoritative parenting practices sebagai perilaku pengasuhan yang dilakukan orangtua di dalam berbagai situasi yang berkontribusi untuk perkembangan psikologis yang sehat pada remaja untuk mencapai tujuan tertentu dengan adanya sikap penerimaan atau kehangatan, pengawasan, dan pemberian otonomi psikologis atau demokrasi yang dilakukan orangtua terhadap remaja. Steinberg juga menyatakan bahwa authoritative parenting practices dibentuk oleh tiga dimensi utama, pertama acceptance/ involvement yaitu sejauhmana remaja memandang atau mempersepsikan bentuk kasih sayang, responsif dan keterlibatan yang dilakukan orangtua seperti membantu menyelesaikan permasalahan yang dihadapi. Kedua strictness/supervision yaitu sejauhmana pemantauan atau pengawasan dan aturan-aturan yang dilakukan orangtua terhadap kegiatan atau hal-hal yang dilakukan remaja. Ketiga, psychological autonomy granting yaitu sejauhmana orangtua memberikan kebebasan kepada remaja tanpa adanya paksaan, disiplin demokratis, dan mendorong remaja untuk mengekspresikan individualitas didalam keluarga.

Berdasarkan beberapa paparan di atas dapat dikatakan bahwa authoritative parenting practices yang dilakukan orangtua memiliki dampak terhadap perilaku remaja, khususnya menumbuhkan kontrol diri remaja dari delinkuensi. Oleh karena itu penelitian ini akan mengungkapkan apakah terdapat hubungan antara persepsi remaja terhadap authoritative parenting practices dengan intensi berperilaku delinkuensi pada remaja.

\section{METODE}

Penelitian ini menggunakan metode korelasi kuantitatif, untuk mengukur hubungan antara persepsi terhadap authoritative parenting practice dengan intensi berperilaku delinkuen pada remaja.

\section{Definisi Operasional}

Persepsi remaja terhadap authoritative parenting practice adalah penilaian kognisi dan afeksi remaja terhadap praktek pengasuhan orangtuanya yang mencakup dukungan emosional, standar yang tinggi, pemberian otonomi yang sesuai, dan komunikasi dua arah yang dapat membantu remaja dalam mengembangkan kompetensi yang ditandai dengan keseimbangan kebutuhan dan tanggung jawab baik secara sosial maupun individual.
Intensi berperilaku delinkuen pada remaja adalah niat atau keinginan seseorang untuk melakukan perbuatan-perbuatan yang bersifat melanggar norma-norma masyarakat atau kelompok sosial, baik norma hukum, norma sosial, norma kesusilaan, maupun norma agama

\section{Populasi dan Sampel Penelitian}

Populasi dalam penelitian ini adalah remaja siswa kelas IX SMP IT di tiga sekolah di Semarang dan tinggal bersama orangtua dengan jumlah populasi total 400 siswa. Dengan taraf kesalahan $5 \%$ populasi sebanyak 400 orang maka sampel penelitiannya adalah minimal 186 orang, dan ditentukan 97 siswa dari satu sekolah untuk uji coba dan 188 siswa dari dua sekolah lainnya untuk penelitian. Pengambilan sampel dalam penelitian ini menggunakan teknik cluster random sampling.

\section{Pengumpulan Data}

Penelitian ini menggunakan dua skala psikologis, yaitu skala persepsi remaja terhadap authoritative parenting practice orangtua dibentuk oleh tiga dimensi utama (Steinberg, 2002), yaitu acceptance/ involvement, strictness/supervision, psychological autonomy granting, dengan 39 item valid (contoh: Saya senang karena selama ini orangtua berdiskusi dengan saya mengenai aturan di rumah dalam penggunaan gadget), serta skala intensi berperilaku delinkuen pada remaja, yang diukur berdasarkan gabungan aspek intensi menurut Ajzen (2005) dan indikator berperilaku delinkuen menurut Jensen (dalam Sarlito, 1999), yaitu aspek tindakan, aspek sasaran, aspek konteks, aspek waktu, dengan 35 item valid (contoh: Saya akan mengajak teman membolos untuk bermain game jika sedang jenuh sekolah).

\section{Analisis Data}

Data yang diperoleh dianalisis dengan menggunakan analisis regresi sederhana untuk menguji hipotesis, dengan program Statistical Packages for Social Sciences (SPSS) Release 2.7. 


\section{Journal of Psychological Science and Profesion (JPSP)}

Vol.2, No.1, April 2018

E-mail: jurnal.psp@unpad.ac.id

HASIL DAN PEMBAHASAN

Uji Hipotesis

Tabel 1.

Rangkuman Analisis Regresi Sederhana Variabel Penelitian

\begin{tabular}{c|c|c|c|c|c|c}
\hline \multicolumn{2}{c|}{ Model } & $\begin{array}{c}\text { Sum of } \\
\text { Square }\end{array}$ & Df & $\begin{array}{c}\text { Mean } \\
\text { Square }\end{array}$ & $\boldsymbol{F}$ & Sig \\
\hline \multirow{2}{*}{1} & Regression & 620,024 & 1 & 620,024 & 6,985 & $\mathbf{0 , 0 0 0}$ \\
\cline { 2 - 7 } & Residual & 16510,205 & 186 & 88,765 & & \\
\cline { 2 - 7 } & Total & $\mathbf{1 7 1 3 0 , 2 2 9}$ & $\mathbf{1 8 7}$ & & & \\
\hline
\end{tabular}

Tabel 2.

Koefisien Determinasi Penelitian

\begin{tabular}{c|c|c|c|c}
\hline Model & $\boldsymbol{R}$ & $\begin{array}{c}\boldsymbol{R} \\
\text { Square }\end{array}$ & $\begin{array}{c}\text { Adjusted } \\
\boldsymbol{R} \\
\text { Square }\end{array}$ & $\begin{array}{c}\text { Standar } \\
\text { Error of } \\
\text { Estimate }\end{array}$ \\
\hline 1 & $-\mathbf{0 , 2 2 8}$ & $\mathbf{0 , 1 3 3}$ & $\mathbf{0 , 0 3 1}$ & $\mathbf{9 , 4 2 1 4 9}$ \\
\hline
\end{tabular}

Deskripsi Hasil Penelitian

Hasil penelitian yang dilakukan adalah sebagai berikut:

Tabel 3.

Kondisi Empiris Persepsi terhadap Authoritative Parenting Practice Orangtua

\begin{tabular}{|c|c|c|c|}
\hline Sangat & Rendah & Tinggi & Sangat \\
Rendah & $\mathrm{N}=20$ & $\mathrm{~N}=142$ & $\mathrm{~N}=26$ \\
$\mathrm{~N}=0$ & $10,64 \%$ & $75,53 \%$ & $13,83 \%$ \\
$0 \%$ & & \\
\hline
\end{tabular}

Tabel 4.

Kondisi Empiris Intensi dalam Berperilaku Delinkuen pada Remaja

\begin{tabular}{|c|r|c|c|}
\hline Sangat & Rendah & & Sangat \\
Rendah & $\mathrm{N}=$ & Tinggi & Tinggi \\
$\mathrm{N}=22$ & 15 & $\mathrm{~N}=8$ & $\mathrm{~N}=1$ \\
$11,70 \%$ & 7 & $4,26 \%$ & $0,53 \%$ \\
\hline
\end{tabular}

\section{DISKUSI}

Hasil penelitian dengan nilai signifikansi sebesar $0,000 \quad(p<0,05)$ dan korelasi $(r)=-0,228$, menunjukkan bahwa terdapat hubungan negatif dan signifikan antara persepsi remaja terhadap authoritative parenting style yang diterapkan orangtua dengan intensi dalam berperilaku delinkuen, dapat diterima.

Remaja merupakan rentang usia transisi dari anak-anak menuju dewasa, yang melibatkan perubahan-perubahan fisik, kognitif, dan sosioemosional. Perubahan-perubahan sosioemosional meliputi tuntutan pada remaja untuk mencapai kemandirian, konflik dengan orangtua, dan keinginan untuk menghabiskan waktu bersama teman sebaya. Di saat yang sama, masa remaja merupakan masa puncak emosionalitas yaitu terjadi peningkatan ketegangan emosi yang dihasilkan dari perubahan fisik dan hormonal (Desiningrum, Indriana, \& Siswati, 2017). Maka remaja kerapkali mengalami konflik dan terkesan menentang orangtua. Pentingnya keberadaan teman sebaya disamping memberikan manfaat positif, bisa menjadikan remaja tenggelam dalam pergaulan yang salah.

Dari hasil perhitungan kategorisasi tabel 2 , intensi dalam berperilaku delinkuen pada subyek tergolong mayoritas rendah. Artinya subyek tidak memiliki kecenderungan berperilaku delinkuen. Di gambar 1, persepsi subyek terhadap authoritative parenting practice orangtua mayoritas adalah tinggi, artinya subyek menilai dan merasakan bahwa terdapat pola asuh autoritatif yang diterapkan oleh kedua orangtuanya. Dari kedua keterangan tersebut dan hasil korelasi kedua variabel, maka dapat disimpulkan bahwa remaja menilai dirinya mendapatkan pengasuhan yang komunikatif dan supportif dari orangtua, sehingga remaja mampu untuk mengontrol diri, dan tidak mudah terjebak dalam pergaulan salah di lingkungan sosialnya. Suatu penelitian menemukan pentingnya kontrol diri terbentuk pada remaja, agar tidak mudah terpengaruh lingkungan teman sebaya, terutama dalam hal penyalahgunaan obat-obatan terlarang (Seglem, Torgersen, Ask, \& Waaktaar, 2015; Meldrum, et. Al, 2017).

Pada penelitian ini variabel persepsi remaja terhadap authoritative parenting practice orangtua mempunyai sumbangan efektif sebesar 1,33\% terhadap intensi berperilaku delinkuen. Sumbangan efektif yang kecil ini dapat disebabkan karena intensi sebuah perilaku itu terbentuk bisa dipengaruhi oleh faktor hereditas dan keadaan lingkungannya. Masa remaja merupakan pembentukan individuasi, dimana tugas perkembangan remaja diantaranya adalah mulai mandiri secara emosional dari orangtua, maka perhatian masyarakat terhadap remaja perlu ditingkatkan, karena remaja banyak beralih pada teman sebaya dibanding orangtua (Fontaine, Brendgen, Vitaro, \& Tremblay, 2016). Penemuan suatu hasil penelitian lainnya, remaja beresiko tinggi untuk menjadi korban, pelaku bullying, dan menyakiti diri sendiri, dan semua bisa menjurus kepada perilaku delinkuen lainnya, maka orangtua juga berkontribusi dalam pengawasan anak remajanya (Barker, Arseneault, Brendgen, Fontaine, \& Maughan, 2008).

Di dalam authoritative parenting practice, orangtua cenderung memberikan kebebasan namun juga mengawasi anak remajanya, dan lebih menekankan pada tanggung jawab remaja dalam semua perilakunya. Suatu hasil penelitian 


\section{Journal of Psychological Science and Profesion (JPSP)}

Vol.2, No.1, April 2018

E-mail: jurnal.psp@unpad.ac.id

menyebutkan bahwa bagaimanapun, pengawasan orangtua terhadap semua perilaku sehari-hari remaja perlu terus dilakukan, pada golongan masyarakat ekonomi rendah, menengah maupun tinggi (Rekker, Keijsers, Branje, Koot, \& Meeus, 2017). Dari hasil wawancara dengan 10 subyek, ditemukan hasil penelitian lainnya dimana remaja menilai bahwa (1) orangtua yang harmonis selalu dibutuhkan mereka, agar tercipta iklim saling menyayangi dalam keluarga; (2) peran ayah dan ibu yang berbeda, dirasakan remaja sebagai peran yang saling melengkapi, ibu adalah sosok yang pengertian dan memberikan kasih sayang, dan ayah adalah figur yang tegas dan mampu menasehati.

Remaja yang banyak dipengaruhi oleh teman sebaya, bisa terjerumus dalam kelompok teman eksklusif atau terlibat dalam aktivitas genk yang bisa mengarah pada perilaku delinkuen atau kriminalitas (O'Bgrien, Dafferna, Chua, \& Thomas, 2013). Maka agar remaja tidak terlalu banyak menghabiskan waktu di luar bersama genk atau kelompoknya, dibutuhkan peran orangtua dalam mengawasi aktivitas anak remajanya, agar mengarah pada berbagai aktivitas positif, seperti belajar/sekolah, bermain dan menyalurkan hobinya (Wight, et.al, 2009).

\section{SIMPULAN}

Ada hubungan negatif dan signifikan antara persepsi remaja terhadap authoritative parenting practice orangtua dengan intensi dalam berperilaku delinkuen pada remaja. Dengan korelasi yang rendah dan kontribusi yang rendah pula. Temuan hasil wawancara adalah, remaja menilai bahwa kemampuan orangtua dalam menjaga keharmonisan keluarga adalah penting, dan peran kedua orangtua yang berbeda namun dirasa remaja bisa saling melengkapi._Saran selanjutnya, penelitian bisa diarahkan pada persepsi remaja terhadap keharmonisan dan peran orangtua.

\section{DAFTAR PUSTAKA}

AhYoo, J. (2017). Developmental changes in the bidirectional relationships between parental monitoring and child delinquency. Children and Youth Services Review. 73: 360-367. https://doi.org/10.1016/j.childyouth.2017.01. 008

Ajzen, I. (2005). Attitudes personality and behavior second edition. Newyork: Open University Press.
Barker, ED, Arseneault, L, Brendgen, M, Fontaine, N, \& Maughan, B. (2008). Joint Development of Bullying and Victimization in Adolescence: Relations to Delinquency and Self-Harm. Journal of the American Academy of Child \& Adolescent Psychiatry. 47 (9): 1030-1038. https://doi.org/10.1097/CHI.ObO13e31817e ec98

Cakır, SG. (2015). Authoritative Approach and Student Empowerment Among University Students. Procedia - Social and Behavioral Sciences. 186 : 151-154. https://doi.org/10.1016/j.sbspro.2015.04.07 8

Darling, N., \& Steinberg, L. (1993). Parenting style as context: in integrative model. Psychological Bulletin, 113 (3), 487-496.

Davisa, AN, \& Carlo, G. (2018). The roles of parenting practices, sociocognitive/emotive traits, and prosocial behaviors in lowincome adolescents. Journal of Adolescence. 62: 140-150. https://doi.org/10.1016/j.adolescence.2017. 11.011

Desiningrum, DR, Indriana, Y, \& Siswati. (2017). Intensi penggunaan gadget dan kecerdasan emosional pada remaja awal. Prosiding Temu IImiah X Ikatan Psikologi Perkembangan Indonesia. Peran Psikologi Perkembangan dalam Penumbuhan Humanitas pada Era Digital. 22-24 Agustus 2017, ISBN: 978-602-1145-49-4. Pg. 65-71.

Fontaine, NMG, Brendgen, M, Vitaro, F, \& Tremblay, RE. (2016). Compensatory and protective factors against violent delinquency in late adolescence: Results from the Montreal longitudinal and experimental study. Journal of Criminal Justice. 45: 54-62. https://doi.org/10.1016/j.jcrimjus.2016.02.01 3

Hurlock, E. B. (2009). Psikologi perkembangan, suatu pendekatan sepanjang rentang kehidupan. Terjemahan Istiwidayanti \& Soedjarwo. Jakarta: Erlangga

Jago, R, Davison, KK, Brockman, B, Page, AS, Thompson, JL, \& Fox, KR. (2011). Parenting styles, parenting practices, and physical activity in 10- to 11-year olds. Preventive Medicine. 52 (1): 44-47. 


\section{Journal of Psychological Science and Profesion (JPSP)}

Vol.2, No.1, April 2018

E-mail: jurnal.psp@unpad.ac.id

https://doi.org/10.1016/j.ypmed.2010.11.00 1

José, OC, Fraguela, AG, Maneiro, L, \& Sobral, J. (2017). Effects of parenting practices through deviant peers on nonviolent and violent antisocial behaviours in middle- and late-adolescence. The European Journal of Psychology Applied to Legal Context. 9 (2): 75-82.

https://doi.org/10.1016/j.ejpal.2017.02.001

Khatoon, N, Hesaria, Z, \& Hejazi, E. (2011). The Mediating Role of Self Esteem in the Relationship Between the Authoritative Parenting Style and Aggression. Procedia Social and Behavioral Sciences. 30: 17241730.

https://doi.org/10.1016/j.sbspro.2011.10.33 3

Kim, S. Y.,\& Ge, X. (2008). Parenting practices and adolescent depressive symtomps in chinese american families. Journal of Family Psychology, 14 (3), 420-435. doi: 10.1037//O893-32OO.14.3.420

Mayseless, O., Scharf, M., Sholt, M. (2003). From authoritative parenting practices toan authoritarian context: exploring thepersonenvironment fit. Journal of Research on Adolescence, 13(4), 427-456

Meldrum, RC, Trucco, EM, Cope, LM, Zucker, RA, \& Heitzeg, MM. (2017). Brain activity, low self-control, and delinquency: An fMRI study of at-risk adolescents. Journal of Criminal Justice. Available online 20 July 2017.

https://doi.org/10.1016/j.jcrimjus.2017.07.00 7

Morgado, AM, \& Dias, MLV. (2013). The antisocial phenomenon in adolescence: What is literature telling us? Aggression and Violent Behavior. 18 (4): 436-443. https://doi.org/10.1016/j.avb.2013.05.004

O'Bgriena, K, Dafferna, M, Chua, CM, \& Thomas, SDM. (2013). Youth gang affiliation, violence, and criminal activities: A review of motivational, risk, and protective factors. Aggression and Violent Behavior. 18 (4): 417-425.

https://doi.org/10.1016/j.avb.2013.05.001
Papalia, D.E., Old, S.W., \& Feldman, R.D. (2009). Human development. Jakarta: Salemba Humanika.s

Rekker, R, Keijsers, L, Branje, S, Koot, H, \& Meeus, W. (2017). The interplay of parental monitoring and socioeconomic status in predicting minor delinquency between and within adolescents. Journal of Adolescence. 59:

155-165. https://doi.org/10.1016/j.adolescence.2017. 06.001

Republika. (2012). Mengatasi Kenakalan Remaja. Diunduh pada 4 Juli 2013 dari http://www.republika.co.id/berita/rol-toschool/tim-jurnalistik-sma-se jakartatimur/12/05/23/m4gut0-mengatasikenakalan-remaja

Sabatine, E, Lippold, M, \& Kainz, K. (2017). The unique and interactive effects of parent and school bonds on adolescent delinquency. Journal of Applied Developmental Psychology. 53: 54-63. https://doi.org/10.1016/j.appdev.2017.09.00 5

Sandu, MC, Pânişoarã, G, Ovidiu, I, \& Pânişoarã. (2015). Study on the development of selfawareness in teenagers. Procedia - Social and Behavioral Sciences. 180: 1656-1660. https://doi.org/10.1016/j.sbspro.2015.05.06 0

Sarlito, S. W. (1999). Psikologi Sosial: Individu dan Teori-Teori Psikologi Sosial. Jakarta: Balai Pustaka.

Seglem, KB, Torgersen, S, Ask, H, \& Waaktaar, T. (2015). Weak etiologic links between control and the externalizing behaviors delinquency and substance abuse in adolescence. Personality and Individual Differences. $\quad 75$ : 179-184. https://doi.org/10.1016/j.paid.2014.11.036

Simmons, C, Steinberg, L, Frick, PJ, \& Cauffman, E. (2018). The differential influence of absent and harsh fathers on juvenile delinquency. Journal of Adolescence. 62: 917.

https://doi.org/10.1016/j.adolescence.2017. 10.010

Steinberg, L., \& Silk, J. S. (2002). Parenting adolescents. In M. H. Bornstein (Ed. 2), Handbook of Parenting (Vol. 1, pp. 103133). Mahwah, NJ Erlbaum 
Journal of Psychological Science and Profesion (JPSP)

Vol.2, No.1, April 2018

E-mail: jurnal.psp@unpad.ac.id

Sudarsono. (2004). Kenakalan remaja prevensi, rehabilitasi dan resosialisasi. Jakarta: PT. Rineka Cipta.

Surabaya Tribunnews. (2016). http://surabaya.tribunnews.com/2016/08/29 /hasil-survei-45-persen-remaja-indonesiausia-13-19-tahun-sudah-merokok.

Sviridova, TV, Lazurenko, SB, Slipka, MI. (2016). Possibilities of the pediatric community in prevention of social risks of teenagers. Procedia - Social and Behavioral Sciences. 217: 1153-1156. https://doi.org/10.1016/j.sbspro.2016.02.13 $\underline{3}$

Wight, VR, Price, J, Bianchi, SM, \& Hunt, BR. (2009). The time use of teenagers. Social Science Research. 38 (4): 792-809. https://doi.org/10.1016/j.ssresearch.2009.0 5.009

You, S, \& Lim, SA. (2015). Development pathways from abusive parenting to delinquency: The mediating role of depression and aggression. Child Abuse \& Neglect. $\quad 46$ : 152-162. https://doi.org/10.1016/j.chiabu.2015.05.00

9

Yusuf, S. (2012). Psikologi perkembangan anak dan remaja. Bandung: PT. Remaja Rosdakarya. 